ADLFI. Archéologie de la France -

INFORMATIONS

Informations

une revue Gallia

Aquitaine | 2009

\title{
Secteur Médoc
}

Jean-Marie Lourenço

URL : http://journals.openedition.org/adlfi/4003

ISSN : 2114-0502

Éditeur

Ministère de la culture

Référence électronique

Jean-Marie Lourenço, «Secteur Médoc », ADLFI. Archéologie de la France - Informations [En ligne], Aquitaine, mis en ligne le 01 mars 2009, consulté le 19 avril 2019. URL : http://

journals.openedition.org/adlfi/4003

Ce document a été généré automatiquement le 19 avril 2019

(c) Ministère de la Culture et de la Communication, CNRS 


\title{
Secteur Médoc
}

\author{
Jean-Marie Lourenço
}

\section{Identifiant de l'opération archéologique : 0225154}

Date de l'opération : 2009 (PR)

1 La deuxième campagne de prospection portant sur le secteur du Médoc a livré des résultats sur le littoral nord de la commune de Montalivet.

2 En décembre 2009, après une série de marées de forts coefficients combinées à un vent d'ouest soutenu, un paléosol tourbeux a été désensablé. À quelques mètres du pied de dune, à 0,15 $\mathrm{m}$ de profondeur, un petit dépôt du Bronze moyen a été découvert.

3 L'ensemble présente 21 éléments : 1 hache médocaine à bords droits, 1 hache à talon, 2 talons cassés, 3 tranchants cassés (1 de hache à talon, 2 de hache médocaine), 1 fragment de hache à talon, 3 autres de hache médocaine, 3 bracelets, 5 fragments de bracelets. Les deux haches complètes composant cet ensemble étaient fichées, tranchants dans le sable, verticales, talons dirigés vers le haut, les autres éléments fragmentés disposés autour. Trois bracelets entiers étaient placés sur les talons des haches, assurant à l'ensemble du dépôt un maintien et une ligature relative.

4 Si les conditions de fouille, loin d'être optimales, n'autorisent pas une grande finesse d'observation, notamment sur la disposition des objets fragmentés, l'absence de contenant céramique est néanmoins une quasi-certitude et seule une enveloppe, en une matière périssable, reste envisageable. Il est toutefois à signaler la présence de morceaux de poterie à gros pastillages pris dans les argiles probablement depuis fort longtemps, dans un rayon de $10 \mathrm{~m}$ autour du dépôt.

Dans le Nord-Médoc et notamment le long de la zone côtière, les découvertes sporadiques d'objets en bronze participent depuis longtemps à l'enrichissement archéologique de la Gironde. L'intérêt particulier de ce dépôt tient à son mode d'enfouissement atypique. Il alimente de ce fait réflexions et interrogations. 
6 Les objets ont-ils été assemblés par les courants dans une cuvette naturelle après la destruction du dépôt par les vagues ou doit-on y voir une cachette intentionnelle de bronzier?

7 La position verticale des haches, l'effet liant des bracelets et l'absence de contenant céramique dans un environnement qui n'était sans doute pas proprement marin il y a 3500 ans, plaident en faveur d'un dépôt en position primaire.

8 Ce dépôt pouvait-il présenter un caractère temporaire? La relative homogénéité des poids de la majorité des fragments permet d'envisager une volonté d'utilisation postérieure, par exemple une refonte.

9 (Fig. $\mathrm{n}^{\circ} 1$ : Montalivet - Dépôt de l'Âge du Bronze moyen)

10 Lourenço Jean-Marie

\section{ANNEXES}

Fig. $\mathrm{n}^{\circ} 1$ : Montalivet - Dépôt de l'Âge du Bronze moyen

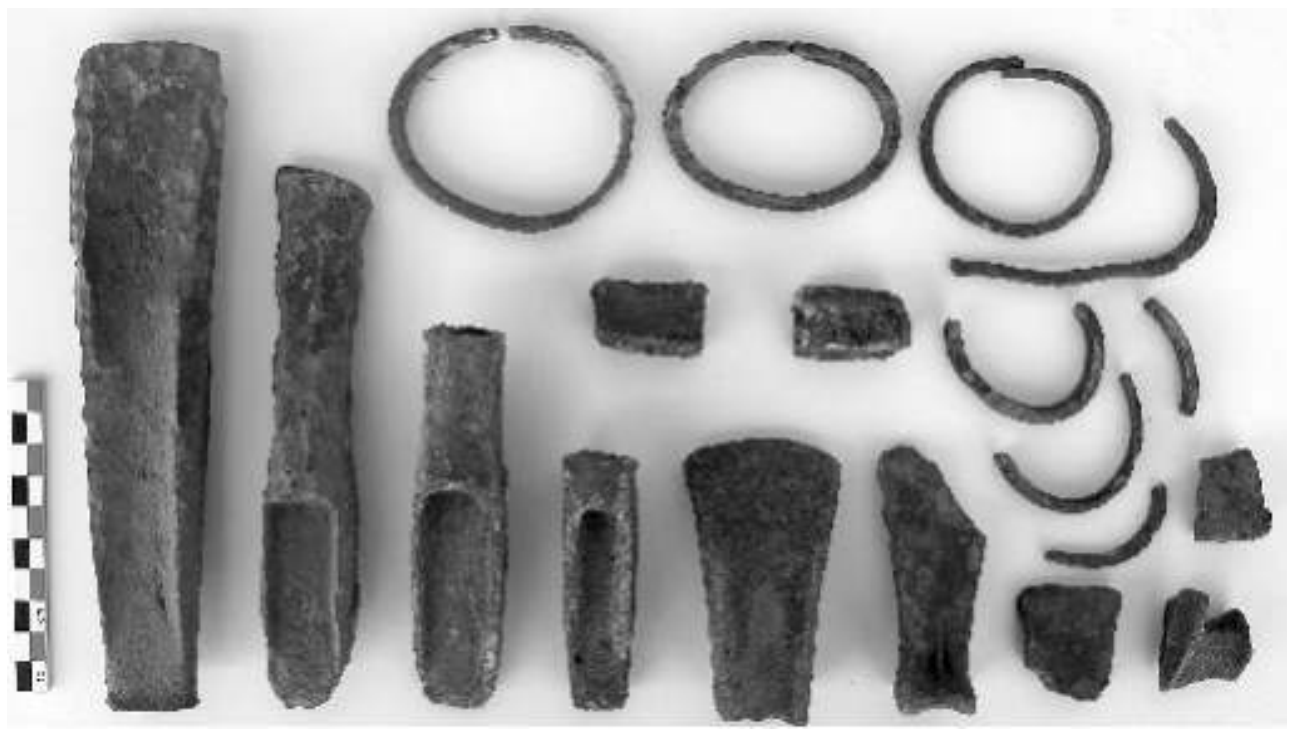

Auteur(s) : Lourenço, Jean-Marie (BEN). Crédits : Lourenço Jean-Marie, BEN (2009)

INDEX

operation Prospection (PR)

Thèmes : bracelet, bronzier, hache, hache à talon, objet métallique, tourbière

Index chronologique : âge du Bronze

Index géographique : Aquitaine, Gironde (33), Vendays-Montalivet 
AUTEURS

JEAN-MARIE LOURENÇO

BEN 